\title{
O MONUMENTO E AS CINZAS: UM ESTUDO DO CONTO A MORTA DE FLORBELA ESPANCA
}

Olga Valeska

Amar um ser é dizer-lhe: "tu não morrerás... Se eu consentisse no teu aniquilamento eu trairia o nosso amor (...)"

Marcel

(...) mas nada de firme, nada de eterno se pode gravar nas ondas, e são elas a pedra de seu túmulo.

F. Espanca

\section{Resumo}

Esse trabalho tem como objetivo refletir sobre a relação morte/amor, a partir do conto $A$ morta, de Florbela Espanca, e pondo em relevo o próprio discurso da autora.

\section{Résumé}

Ce travail a pour objet des réflexions sur le rapport mort/amour, à partir de l'analyse de l'ouvre A Morta, de Florbela Espanca, et en mettant en relief le discours de l'auteur. 
O tema desse trabalho pode causar estranhamento em uma sociedade em que a morte foi esvaziada de sentido e afastada da consciência como um tema maldito. Porém a morte, mesmo afastada, ou porque afastada, deixa sempre um lugar vazio que permanece como um monumento invisivel que insiste em projetar sombras sobre a claridade apaziguadora do cotidiano. Assim, a morte, mais do que nunca, marca a sua presença enquanto tabu, lugar de absurdo que fere as certezas onipotentes do mundo moderno: "A morte revela o caráter absurdo da existência humana"', e faz emergir, em sua profundidade, o rasgo, a cisäo irônica e trágica do homem enquanto ser-para-a-morte.

Os sistemas religiosos, morais e sociais tentam obturar, em vão, esse vazio que sempre ameaça transgredir o espaço seguro da vida e romper a pelicula fina que isola o "ser" e o "não-ser". Nesse sentido, tematizar a morte é forçar a abertura de uma fenda que viola a certeza desse isolamento e traz à tona a (im)possibilidade de pensar a própria ausência:" "O pensamento da morte não corresponde à imagem de nossa própria morte, a imagem de nossa morte escapa à nossa capacidade de representaçāo".2

O sem-sentido da morte esvazia o significado da existência e constitui o primeiro enigma proposto à lógica humana. E esse enigma instala-se no próprio tecido do simbólico à partir do qual os sistemas de relaçōes sociais são construidos. O modo de vida de um povo depende, em muitos aspectos, da maneira como a morte é pensada e representada no imaginário social.

Dessa maneira, pode-se dizer que o sentido do "ser" emerge desse espaço de indagação sobre a morte (indagação que sempre permanece sem resposta) configurando um marco que centra a construção do universo humano. Porém, esse centramento é paradoxal, já que instaura um lugar vazio que sempre ameaça tragar, num movimento de refluxo, todo o significado desse mesmo universo construido.

O conto A Morta, que analiso neste trabalho, faz parte da obra As Máscaras do Destino, dedicada a um morto. Este conto é, assim, uma tentativa de plastificação, através da linguagem, da dor humana diante da morte. "Mas eu não queria, nāo queria que o meu morto morresse comigo, näo queria. E escrevi estas páginas..." (As Máscaras doDestino, p.24)

Ora, dizer o outro, ou melhor, dizer sobre o outro (morto) é. em última instância, um trabalho de elaboração do luto. É o 
sepultamento do corpo que testemunha a violência da perda e, ao mesmo tempo, uma preservação de sua memória. A escrita reconduz a morte para o lugar do simbólico e, tornando-se inscriçăo lapidar, fixa um lugar vazio e faz reverberar o silêncio que interroga a realidade de uma ausência.

Nesse sentido, o discurso é destituição e edificação na medida em que o corpo morto é alienado de sua materialidade e divinizado na instância da palavra: inscrito, ele não conhecerá a comupção da morte. Mas essa divinização demanda uma distensão tal que dilacera todo o tecido da linguagem - Deus é o lugar do indizivel, espaço vazio, irrepresentável: "Deus é inventado nesse centro em branco, nessa falha do simbólico que é também seu fundamento". ${ }^{3}$ Dai as repetiçōes exaustivas que ocorrem nas fórmulas encantatórias e nas ladainhas. Dai a tautologia e a circularidade dos textos misticos (ou eróticos) que tentam alcançar esse Outro divino (ou divinizado).

Ergue-se, nesse gesto, o monumento/totem (torre de Babel) que busca alcançar a divindade mas que sempre se desmancha na confusão e na insuficiência da linguagem. As palavras se repetem, agonicamente, numa luta desigual em direção ao impossivel. É essa a frustraçäo do sujeito que ao buscar um diálogo com o Outro, só consegue exasperar o vazio da "não pessoa", o "ele" ausente que não participa da elocução, não responde ao chamado encantatório da palavra e se dispersa, se decompöe em fragmentos que fazem eco na voz do próprio sujeito poético.

O sujeito busca reter a matéria do objeto amado (o morto) e só encontra sua própria imagem refletida, fraturada, diluida nos fragmentos de linguagem. Nesse sentido, o "eu", e o "outro" participam da mesma dissoluçäo, do mesmo processo de decomposição.

O que resta ao poeta - consciente dessa dispersão que não marca senão seu próprio vazio de ser senão sentir-se como Fernando Pessoa, tão real como uma metáfora?^

- Monumento escrito é a representação da falta que transborda do lugar vazio a partir do qual é erguido o deus/totem, - Tudo/Nada da condição insuportável de ser mortal.

Nesse sentido, é na própria contemplação poética da morte que emerge e se constitui a ideia de totalidade e é na própria 
decomposição da matéria perecivel que se pode conceber a eternidade. O corpo morto é, assim, um lugar de intervalo entre a contingência de "ser mortal" e o desconhecimento do qual "tudo" pode ser constituido. É a fenda que se abre mediante a (im)possibilidade do "não ser" e do infinito.

No conto A Morta, a protagonista traça um percurso de travessia entre o mundo dos mortos e o dos vivos em direção às ondas de um rio: "A Morta caminhava num passo de morta, um ciciar de brisa na folhagem; (...) as pupilas sem brilho não tinham olhar, e viam. A Morta sabia onde ia" (A Morta, p.36). O texto começa e termina com esse caminhar e, nesse ritmo lento e compassado, a narrativa instaura um espaço de estranhamento, um lugar constituido pelas lembranças de uma morta: "A Morta ia a lembrar-se, que os mortos também se lembram; na solidão do túmulo há tempo e sossego para lembrar". (A Morta, p.36)

O conto é, dessa forma, um testemunho, porém a narrativa é feita na terceira pessoa (ela), a "não-pessoa". A protagonista não toma a palavra narrativa, não tem nome, nem voz: ela é falada pelo texto que se alimenta, no entanto, da matéria de sua memória.

Assim, à guisa das lembranças de um "sujeito" morto, o texto de Florbela Espanca cria uma instância temporal cíclica, onde os quadros se repetem em movimentos ritmados, à semelhança das narrativas míticas:

Uma musa de curvas sensuais, num túmulo de poeta, cerrava languidamente os olhos e fazia com a boca 0 gesto de quem beija. Um sapo enorme, de olhos magníficos como estrelas, lançava a sua nota rouca, refastelado num fofo leito de lírio (A Morta, p.35)

O emprego do imperfeito do indicativo dá uma ideia de continuidade aos movimentos descritos nesse espaço. O mundo dos mortos, dos "outros mortos", é um lugar de repetiçōes vãs e vazios reiterados: "Um suicida escavando a terra com as unhas, procurava os seus sonhos por que se tinha perdido" (A Morta, p.35). Diferente do que ocorre com a protagonista, a morte dos "outros" não abre espaço para os sonhos: "os outros mortos, bem mortos, dormiam pesadamente" (A Morta, p.35). Eles esquecem os sonhos e sacrificam a continuidade dinâmica da vida, para, num gesto indiferente, tomar a postura definitiva da morte: "Um dia, tinham pendido os braços num gesto de fadiga e tinha ficado assim, pelos séculos dos séculos" (A Morta, p.37). 
$\dot{E}$ interessante observar que a indiferença é uma marca tanto do mundo dos mortos quanto dos vivos e é caracterizada, principalmente, pela ausência de sonhos. No entanto, a Morta carrega, encerrados no interior de seu esquife, todas as suas lembranças, todos os seus sonhos:

$E$ agora, as cartas do noivo, o retrato do noivo. $E$, piedosamente, cuidadosamente, não fosse esquecer alguma pétala de flor, (...) algum pedacinho de papel onde as queridas mãos morenas ine tinham traçado o nome, tudo the levaram como uma divina of erta a um ser divinizado. (...) para que nada ficasse a gelar lá fora, no frio glacial da indiferença deste mundo que transe as almas e as coisas. (A Morta, p.36-37)

Assim, o universo da Morta fecha-se em uma metáfora uterina onde vão ser guardados todos os sonhos, todo o devir interceptado pela morte: "Depois, a tampa da caixinha tombou brandamente, entre o ciciar dos soluços, e toda a brancura se apagou; uma noite de luar que se cerrasse em sombras" (A Morta, p.37). E esse fechamento produz um isolamento, um lusco-fusco que separa a Morta, tanto do mundo dos vivos, quanto dos mortos. Porém, o retorno ao ventre materno é uma outra face de Tánatos, onde o desejo de realização plena do ser (ou dos sonhos) se confunde com a renúncia à vida.

E lá foi... Desceu os degraus da escada, baloiçada no seu esquife branco, com a cabeça tonta do perfume das flores e dos seus sonhos de amor encerrados com ela, como se lá tivesse encerrado, numa suprema oferta, todas as primaveras que no mundo haviam de florir depois dela. (A Morta, p.37)

Dessa maneira, nesse conto, não é o amor (na dimensão do humano), não é a vida, mas a plenitude pela vivência do amorl morte que é buscada. E essa busca transgride a condição humana que se realiza, em última instância, no transe da morte: "A autenticidade humana consiste precisamente em enfrentar esta suprema possibilidade, que torna impossivel toda e qualquer posterior possibilidade". No conto, o momento da morte assume a imagem de uma entrega amorosa:

Sentia um êxtase sobre humano, num assombroso sair de si, numa prodigiosa transfiguração de todas as 
fibras do seu ser, a pressão de uns dedos quentes que lhe desciam as pálpebras sobre as pupilas paradas. Uma boca, que ela nunca sonhara tão macia e tăo fresca, roçara-lhe a maciez e a frescura da sua (...) (A Morta, p.36)

Assim, a morte consuma-se na entrega extática a um amor mistico que transborda na admissão da falta, na passividade absoluta do corpo morto. A busca da plenitude ultrapassa, dessa forma, as fronteiras do humano e o aniquilamento se confunde com a vivência totalizadora da morte. No texto, o chegar ao fim, o desaparecer como consequência da morte não é ignorado, porém recusado, ou melhor, denegado no excesso que essa vivência evoca.

Ora, a desagregação do corpo também constitui um excesso: é a entrega máxima, a aceitação inquestionável do destino do "ser-mortal". A entrega do corpo aos efeitos da morte, em última instância, é uma doaçäo de si mesmo, é um retorno à plenitude da indiferenciação. NNa Cabala, a imagem do excremento e do objeto putrefato confunde-se, em um espelho invertido, com a imagem do ouro mais fino, mais puro. No conto que estamos analisando, essa inversão também acontece, porém, de maneira velada: em várias passagens a narradora colore de dourado a face denegada da morte:

Os sete palmos brancos onde as flores dormiam de encontro à carne branca da virgem eram como um enxame de abelhas de ouro: zumbiam lá dentro todas as litanias de amor, batiam desvairadamente os coraçōes dos cravos, abriam-se sedentas as pequeninas bocas das mil florinhas de lilás (...) (A Morta, p.38)

Essa ideia evidencia-se de maneira mais patente se confrontarmos a passagem citada acima com esta outra: "Para quem sabe ouvir, há vibrações de carnes mortas nos túmulos brancos das que morrem puras, como que um frémito brando de erva a crescer..." (A Morta, p.36)

Nesses exemplos, a face da morte ligada à decomposição da carne (e que é, como observamos, denegada no texto) reaparece por entre as imagens ligadas à fertilidade e à fermentação dos sonhos de amor.

Essa ideia de fermentação relaciona-se também com os 
vapores perfumados das flores que sintetizam, principalmente, a subjectividade da Morta (sonhos, desejos, lembranças, etc.). No entanto, se levarmos em conta que o perfume (per + fumas) também pode ser obtido da exalação de líquidos e unguentos odorificos, e da queima do incenso, essa palavra se abre para um significado mais profundo: tanto o fumo do incenso, quanto o unguento associam-se a rituais (funerários ou iniciásticos) de purificação e passagem. Dessa maneira, a palavra "perfume", remete à ideia de transcendência (com toda a carga de transgressão que essa palavra evoca), mas também para o interdito da morte.

Sobre a relação transgressão/interdito, Maria Ester Maciel em seu trabalho Cemitério de Papel, afirma:

A transgressão, segundo Bataille, suspende o interdito, sem entretanto, suprimi-lo. Ela o mantém, completando-o. E é no momento dessa supressão, em que 0 interdito ainda atua, que emerge a angústia, sentimento intrínseco à experiência do pecado: ' $\mathrm{Ai}$ esconde-se o suporte do erotismo e se encontra, ao mesmo tempo, o suporte das religiöes'. ${ }^{5}$

E o texto de Florbela Espanca localiza-a nessa intercessão entre a transgressão e o interdito, entre a plenitude e a morte. Sua escrita erotiza as bordas da falta que o corpo morto presentifica.

Nesse aspecto, o conto $A$ Morta expõe as rachaduras do monumento (altar ou túmulo): é a fresta e não a pedra que é edificada pela palavra. Toda a brancura que envolve o corpo morto näo acalma a inquietação que essa presença evoca, ao contrário: força o escancaramento do espaço marginal da morte.

O monumento é, dessa forma, a sobra do objeto que falta, é o seu excesso, o desejo de permanência que reitera o absurdo do não ser. Erguê-lo é tentar negar a ausência e, nesse mesmo gesto, sublinhar seu espaço vazio: "(..) todas as altas torres brancas de seus sonhos, tudo era tão leve, tão leve, que a caixinha de sete palmos pesava menos que uma pena de colibri". (A Morta, p.37)

Assim, entre o monumento e as cinzas, entre a permanência e a desintegração do ser, queima o desejo que ergue uma torre de fumo diante da eternidade do Outro divinizado: "O grão de incenso que, sobre o altar, caiu mais cedo, ardeu mais cedo; foi 
apenas um grão de incenso (...)" (As Máscara do Destino, p.21)

O incenso, para exalar perfume, precisa queimar. Nesse aspecto, a palavra "perfume" remete ao elemento igneo que sinaliza a destruição e a transformação dos corpos, sendo que, na alquimia, ele é a energia que preside a transmutaçảo dos elementos e, também, a purificação e a transfiguração no plano humano.

Porém, se ligado ao elemento úmido, a palavra perfume aponta para a ideia de geração da vida (gestação), mas também para a morte (decomposição). É interessante observar que a aproximação do noivo, no instante designado como "encantamento", é descrito como uma condensação de perfumes que se liga, significativamente, à ideia de poesia:

Começou depois o encantamento. Todas as tardes, à hora em que o crepúsculo, todo vestido de glicinias, descia com a doçura dumas pálpebras que se fechassem, o perfume das rosas, dos cachos de lilás, das suas recordaçōes de amor encerradas com ela, fazia-se mais denso, corporizava-se, torrava-se nuvem, unguento divino que a inundava, que a aromatizava toda. Os passos, letras de um poema que ela sabia de cor, mal se ouviam, perdidos ainda no coração da cidade dos vivos... Mas agora, vinham mais perto (...) tomavam posse das pedras do caminho da silenciosa cidade dos mortos ( $A$ Morta, p. 38)

O noivo não se constitui enquanto ser material, ele é imagem de poesia, perfume ou reminiscência que se mantém como sensação física sempre presa aos sentidos do corpo. Ele é um ponto difuso de intercessão que transita entre dois mundos e, paradoxalmente, é ausência que se mantém enquanto forma fugidia.

Nesse contexto, o diálogo que se estabelece é uma mistura de essências imateriais da qual as palavras nāo podem participar:

Essência de almas, as almas tocavam-se e era tão cândido esse choque, que as misteriosas forças desse fluido criavam outros fluidos, sopros, hábitos de almas, (...) as bocas ficavam mudas (...) os sons eram imateriais e os gestos intangiveis, e o perfume que é a alma dos sentimentos, nảo era mais pesado que uma essência de perfumes. ( $A$ Morta, p. 38) 
No entanto, enquanto substância imaterial, a natureza do Outro é sempre decepcionante. Assim, no conto, a plenitude do encontro abre-se para o ritmo lacunar da espera: "Mas, uma tarde, a Morta esperou em vão, e esperou outra, e outra, e outra ainda, em infindáveis horas de infindáveis tardes" ( $A$ Morta, p. 39)

O Outro reenvia para o "sujeito" sua própria inconsistência plena de vazios: "O sujeito é riinguém. Ele é despedaçado, decomposto. E ele se bloqueia, é aspirado pela imagem, ao mesmo tempo enganadora e realizada do outro, ou, igualmente, por sua própria imagem especular". ${ }^{\circ}$ Dessa maneira, pode-se dizer que o "sujeito" é um espaço vazio, que redimensiona em si mesmo a falta do outro - a Morta reduplica cada gesto, cada passo do noivo: "... foi então que ela puxou para si a porta do jazigo que dava para a morte" (A Morta, p. 39)

E esse esvaziamento suspende todos os limites e obriga o "sujeito" a uma busca por um ponto além da morte - indagação cega do humano diante da perplexidade de seu próprio silêncio:

Debruçou... Marulho de ondas... E a morta foi mais uma onda, uma onda pequena, uma onda azul na taça de prata a faiscar... Isso aconteceu.

\section{Notas}

' SOUZA MARANHĀO, 1992, p.71.

2 SOUZA MARANHĀO, op.cit., p.65-66.

3 POMMIER, 1991, p.76.

+ MACIEL, 1990, p.99.

5 MACIEL, op.cit., p.35.

6 MACIEL, op.cit., p.

Referências bibliográficas

BATAILLE, George. O erotismo. Trad. Antônio Carlos Viana Porto Alegre: L\&PM, 1987.

BLANCHOT, Maurice. O espaço literário. Trad. Álvaro Cabral. Rio de Janeiro: Rocco, 1987.

BRANDÄO, Jacyntho Lins e SANTOS, Magda Guadalupe. Morte $e$ amor. Ensaios, FALE, $1983 / 84$. 
CASTELLO BRANCO, Lucia. O que é escrita feminina. São Paulo: Brasiliense, 1991.

- A traição de Penélope. Uma leitura da escrita feminina da memória. Belo Horizonte: UFMG, 1990. (Tese de Doutoramento).

COOPER, J.C. Taoismo, o caminho mistico. Trad. João Azenho Júnior. São Paulo: Martins Fontes, 1972.

ESPANCA, Florbela. As máscaras do destino. In: Obras completas de Florbela Espanca. Vol. IV. Lisboa: Publicaçōes Dom Quixote, 1985.

FORTUNE, Dion. A cabala mistica. Trad. Mário Muniz Ferrreira. São Paulo: Passamento, 1957.

GUIMARÃES, Fernando. Simbolismo, Modernismo e Vanguarda. Lisboa: Imprensa Nacional, 1981.

JURANVILLE, Alain. Lacan e a filosofia. Trad. Vera Ribeiro. Rio de Janeiro: Zahar, 1987.

KRISTEVA, Julia. Sol negro, depressão e melancolia. Trad. Carlota Gomes. Rio de Janeiro: Rocco, 1989.

MACIEL, Maria Ester. Cemitério de papel (sobre a atopia do EU de Augusto dos Anjos). Belo Horizonte: UFMG, 1990. (Dissertação de Mestrado). LSOUZA MARANHÄO, José L. de. $q u e$ é morte. São Paulo:
Brasiliense, 1992 .

PERRONE-MOISÉS, Leyla. Aquém do eu, além do outro. São Paulo: Martins Fontes, 1982.

SCHOLEM, Gerhon G. A cabala e seu simbolismo. São Paulo: Perspectiva, 1988.

STEINER, George. As idéias de Heidegger. Col. Mestres da Modernidade. Trad. Álvaro Cabral. São Paulo: Cultrix, 1978.

POMMIER, Gérard. A exceção feminina, os impasse do gozo. Rio de Janeiro: Zahar, 1991. 